\title{
EVALUATION PROTOCOLS IN SCIENCE LABORATORY LEARNING THROUGH ICT TECHNOLOGIES
}

\author{
${ }^{1}$ Lakshmi S Bose \\ ${ }^{1}$ SNM College, Maliankara, \\ Ernakulam, Kerala, \\ India-683516
}

Article DOI: https://doi.org/10.36713/epra6573

\begin{abstract}
Science Laboratory learning using ICT, evaluation protocol is an important part of quality of assurance and to provide feedback for teaching and learning. Virtual lab is widely used ICT technology for the last five years to asssit new faculties in sceince. In this study, we focuss the purpose of assement and raising various difficulties associated with current evaluation techniques in learning and teaching. Assessment is based on test which includes different types of questionnaire for undergraduate students $(N=150)$. Index of learning is conducted among these students, identified reflective and non-reflective learners. From our results, it is difficult to assess student's knowledge gained from traditional or virtual classroom environment from single questionnaire protocol, especially for Visual-Verbal aspects in MCQ approach. Essay type questionnaire and Yes/No questions, the method is constrained to find solutions. We also discuss dependable factors and its percentage affecting for different questionnaire. The Cronbach's alpha value is high for descriptive type questionnaire rather than MCQ, which show internal consistency, is high for descriptive type. T-test is conducted for the variation from one type questionnaire with combination type questionnaire. Current evaluation method does not fulfill the actual goals and this will lead to even misleading the assessment criteria rather than what they gained.
\end{abstract}

\section{INTRODUCTION}

On-line platform for science learning creates a challenging enviroment amoung undergraduate students. Due to covid-19 pandemic situation, educational institutions/universities mostly prefer online learning platforms to met the requirements for graduation. Many studies conduted in the past for the enchancement in learning and education through ICT technologies [1-2]. Hence raise the question that what are the evaluation methods required for the proper, valid results in learning assesment. Oliver (2000) developed a strategy to evaluate the use of technologies in education. To understand more about learning as well as teaching, assessment protocol is essential [11]. Proper laboratory learning is an integral component in science education [9-10]. Continuous assessment helps to evaluate a learner's understanding and knowledge about the subject even if they having different abilities
[15]. Definitely ICT enabled laboratory learning like animation, simulations and videos which the experiment is described can provide deep understanding about concepts, experimental procedure and make it more interesting one to students[1,12-13]. In this study, we are not following traditional experimental laboratory, but focusing ICT enabled experiments using virtual labs and checked current assessment methods/protocols/criteria is sufficient or not in science laboratory learning.

The three main purposes for assessment include (1) decision making (action), (2) evaluation for conceptual understanding and (3) measurement of cognitive load and skills $[4,5,6]$. Determining student's attitude towards problems is usually difficult to evaluate [8]. An important requirement is the type of questions raised for finding a particular answer. In science learning, laboratory based assessment cannot 
be generalized in one type of questionnaire hence we are opting types of questions and try to find out an effective method for the current evaluation scenario.

\section{METHODOLOGY}

This study is carried out under MHRD project in collaboration with titled Virtual Labs (http://www.vlab.co.in). Here purposive sample $\mathrm{N}=150$, undergraduate science students from Mahatma Gandhi University were taken to perform four science virtual lab experiments, two each from Electronics and Mechanics Virtual labs.

The students were selected based on their academic results and they do not have experience in real lab environment. Assessment is based on test which includes different methods of questionnaire. The tests were carried out after performing the experiments in Virtual environment. These assessments can be also used to measure the knowledge attained by the students from virtual environment.

This is to identify which test is most convenient for the student's evaluation and what are the drawbacks if we use one particular method like Multiple Choice Questions (MCQ). The student's performance cannot be assessed by single method, if some have ability to solve particular type of approach.

\section{Phase I}

- According to Index of learning model, the four dimensions of learning styles [14], we divided the students into four groups.

\begin{tabular}{|l|l|}
\hline 1 & $\begin{array}{l}\text { Sensory: go through the fact } \\
\text { Intuitive: try to understand the meaning }\end{array}$ \\
\hline 2 & $\begin{array}{l}\text { Visual: prefer for visual representation } \\
\text { Verbal: prefer explanation with words }\end{array}$ \\
\hline 3 & $\begin{array}{l}\text { Active: prefer group work and try to figure out problems. } \\
\text { Reflective: try to find out a solution }\end{array}$ \\
\hline 4 & $\begin{array}{l}\text { Sequential: overall understanding not into depth. } \\
\text { Global: firstly try to understand the basics and then find solution }\end{array}$ \\
\hline
\end{tabular}

Here we used traditional classroom and virtual lab environment, and try to teach these experiments effectively for students. Index of learning is evaluated by using multiple choice questionnaires (MCQ), most of the students prefer Visual-Verbal learning styles (N92), Sensory - Intuitive (N-11), Active - Reflective (N10), Sequential - Global (N-39). Here also it is found to be difficult to prepare single type questionnaire to assess all the four aspects in learning styles.

\section{Phase II}

After teaching, allowed the students for doing real lab and virtual lab. Assessment is based on test/exam which includes different types of questionnaire. For this phase rather than learning styles, we try to evaluate the depth of knowledge gained from traditional and virtual classroom. The questionnaire is prepared covering four experiments as total 45 questions includes 20 MCQ questions (1 marks), 10 descriptive questions (5 marks), 5 essay type questions (10 marks), and 10 yes/no questions (1/2 marks). All the questions are prepared by making criteria that, to find the solution for one problem, questions are from all four different types. Example: To measure the conceptual learning about ohms law, questionnaire is prepared as follows Eg: MCQ: What is the ratio of voltage and resistance?

Descriptive: What is ohms law?
Essay: Explain ohms law using circuit diagram with examples?

Yes/No : Voltage in circuit can be calculated if current and resistance is known?

The questionnaire based assessment is conducted after real lab and virtual lab, each type of questions is individually tested and analyzed among students.

\section{RESULTS AND DISCUSSIONS}

From Fig 1 \& 2, simulations using virtual environment allow students to control the parameters of the experiment to get maximum knowledge and can attain more about the concepts with application level. Score attained by the students increased in virtual laboratory. Most of students irrespective of their learning style, scored well $(<80 \%)$ for all types of questionnaire in virtual environment. From our results shows that both real lab and virtual lab, students gained well score for descriptive and essay type questions but low marks in MCQ for the question which is asked in different type. It clearly indicates that understanding and depth of knowledge cannot assess by only using MCQ approach. Yes/ No questions are not a valid type of evaluation method for science learning.

To measure the internal consistency/ reliability of the questionnaire, we tested cronbach's alpha.

The results are shown in the table given below 
ISSN (Online): 2455-3662

EPRA International Journal of Multidisciplinary Research (IJMR) - Peer Reviewed Journal Volume: 7 | Issue: 3 | March 2021|| Journal DOI: 10.36713/epra2013 || SJIF Impact Factor 2021:7.147 ||ISI Value: 1.188

\begin{tabular}{|c|c|c|c|c|c|}
\hline $\begin{array}{c}\text { Type of } \\
\text { questionnaire }\end{array}$ & $\mathbf{N}$ & $\begin{array}{c}\text { Sum of item } \\
\text { variance }\end{array}$ & $\begin{array}{c}\text { Standard } \\
\text { deviation(SD) }\end{array}$ & Cronbach's alpha & SEM \\
\hline MCQ & 45 & 1.65 & 1.44 & 0.45 & 0.08 \\
\hline Descriptive & 45 & 1.95 & 0.89 & 0.76 & 0.06 \\
\hline Essay type & 45 & 1.55 & 0.75 & 0.58 & 0.09 \\
\hline Yes/No & 45 & 0.24 & 0.4 & 0.01 & 0.1 \\
\hline
\end{tabular}

The alpha value is high for descriptive type questionnaire rather than MCQ, which show internal consistency, is high for descriptive type. This may due to some of the facts that,

MCQ test, students are asked to answer from options given even if they can answer randomly. This type of questions will be useful only for problem solving. But broad coverage and infinite sampling can be done by using this type of questionnaire. But major drawback for this method is that teachers cannot test knowledge based on theories and depth of knowledge. There is also a possibility for the students who can guess appropriate answer to the question.

Descriptive type questions are used to understand the procedure to the problem. Step by step evaluations can be done for this type. Good explanations, writing skills, depth of knowledge can be easily understood. It is a time consuming method and students with high memory capacity can have a tendency to gain maximum scores by this questionnaire.

Essay type questions are similar to descriptive type, time consuming helps to evaluate the general idea called open ended type questions. Here learning skills cannot be calibrated especially for laboratory work. Students can answer the questions easily with a very few constraints.

Yes/No questions where students can accept or decline the answer, not a method to evaluate deep knowledge due to lack of content. Questionnaire itself is a restriction and not at all met assessment criteria.

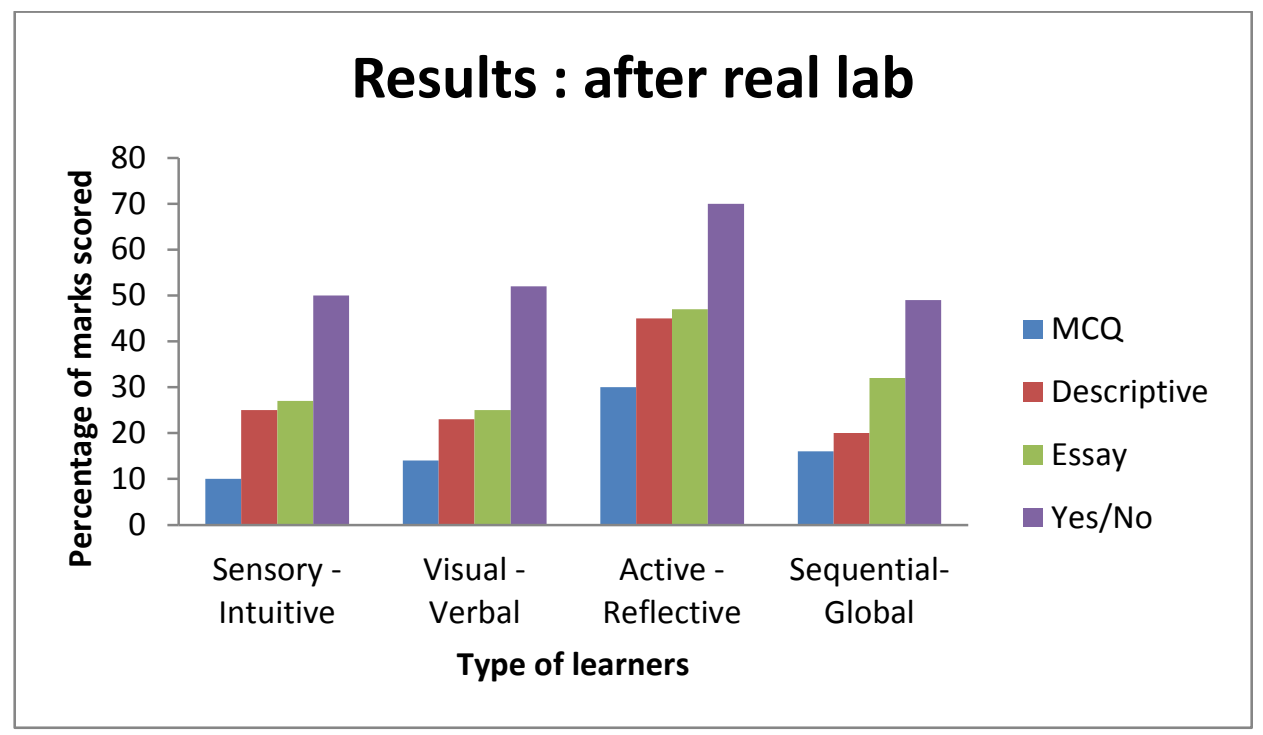

Figure 1. Results for different type questionnaire for Electronics \& Mechanics after real lab 


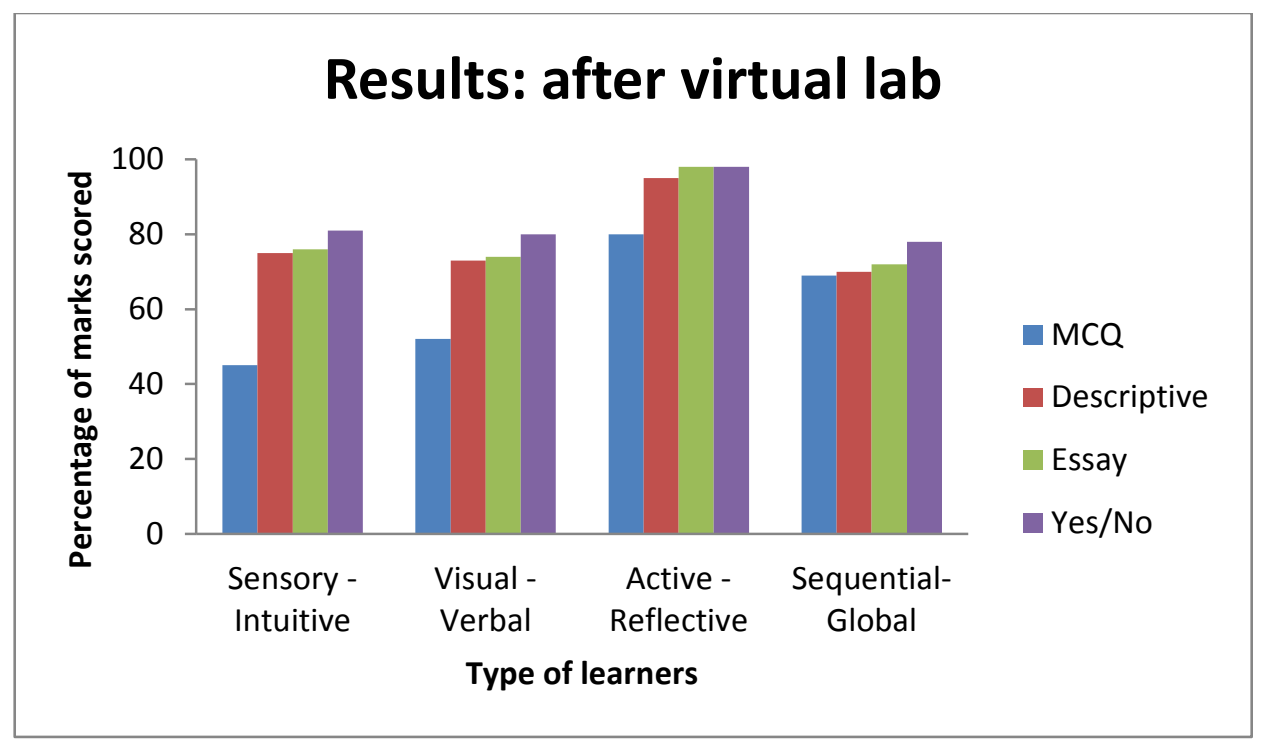

Figure 2. Results for different type questionnaire for Electronics \& Mechanics after virtual lab

From instructors point of view, factors that are dependent on the evaluation of students from their academic results (Fig 3). Most interesting factors are included at which the evaluation may show difficult due to improper assessment pattern to achieve their goals.

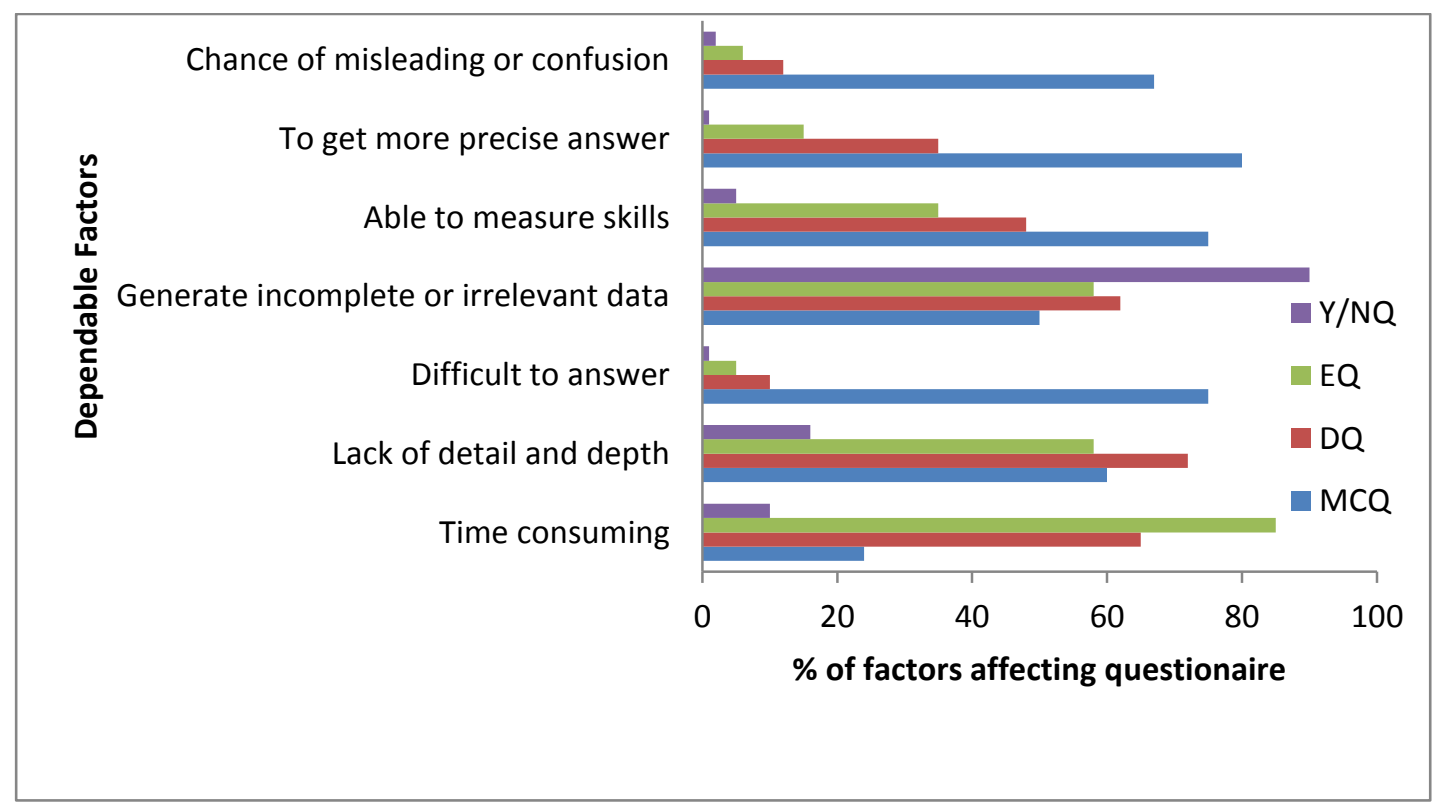

Figure 3. Dependable factors and its percentage affecting for different questionnaire

The questionnaire which includes only MCQ (mostly problem based questions), the students who have the ability to find the final answer gained scores. The descriptive questionnaire is based on problems by here we allow the students to allow step by step procedure to find final answer. Essay type questionnaire, here we allow the students to explain the problem with concepts rather simply studying the equations. Yes/No question, this method constrained for the students and there is possibility to get right answer by random selection.

We have conducted t-test which shows the variation from one type questionnaire with combination type questionnaire. 
ISSN (Online): 2455-3662

EPRA International Journal of Multidisciplinary Research (IJMR) - Peer Reviewed Journal Volume: 7 | Issue: 3 | March 2021|| Journal DOI: 10.36713/epra2013 || SJIF Impact Factor 2021:7.147 ||ISI Value: 1.188

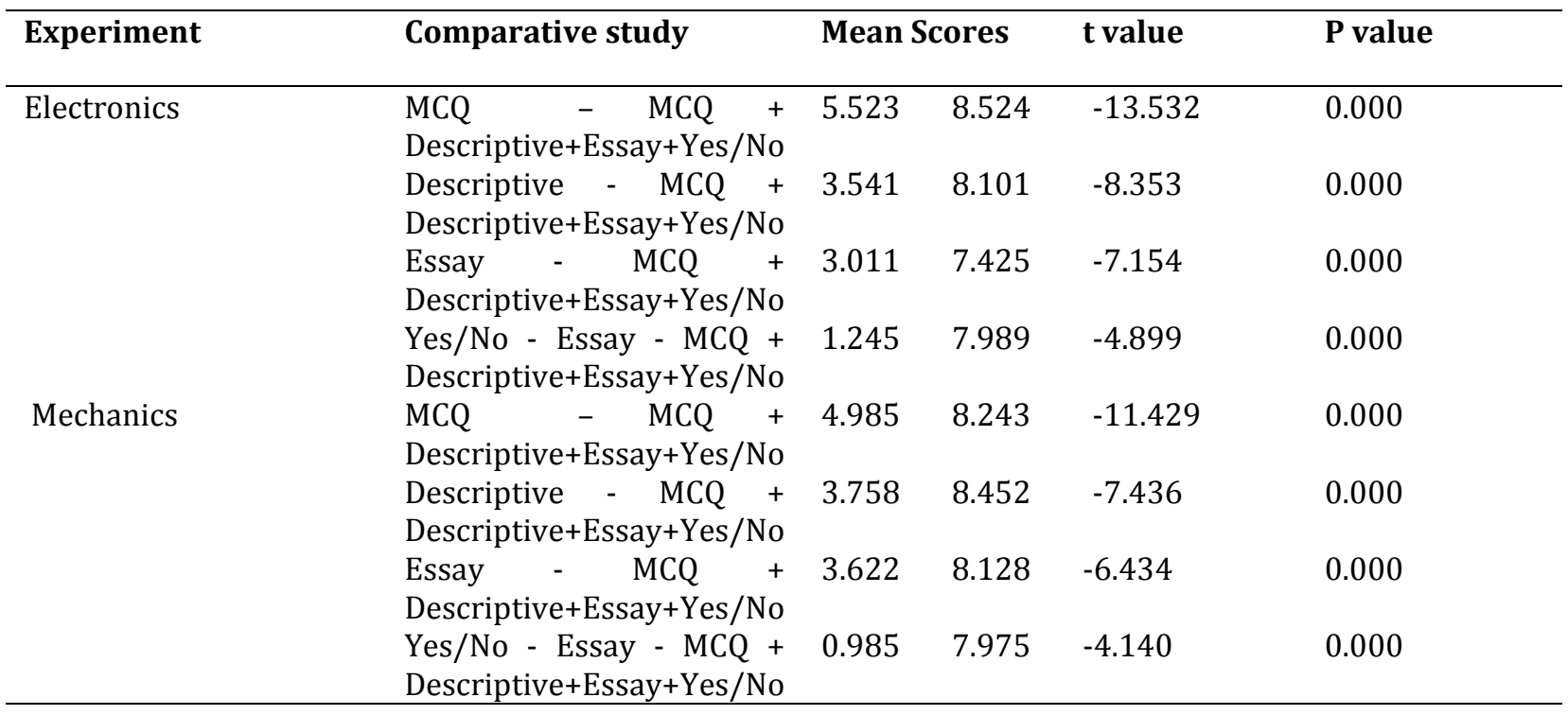

Our results shows combined questionnaire can analyze and is to dig the learning knowledge of each student. Hence we suggest an evaluation protocol for the assessment in learning and teaching based on flowchart 


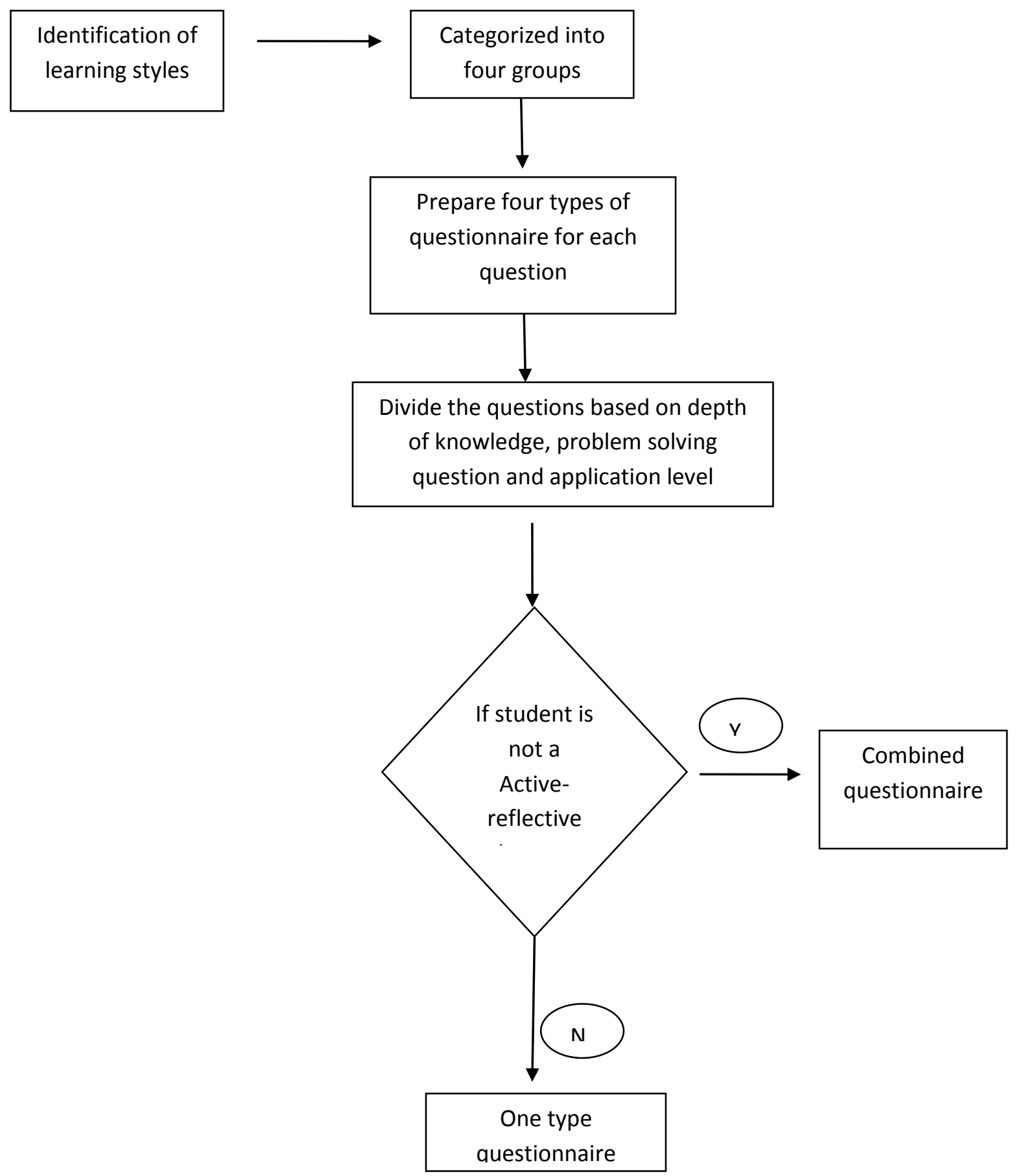

\section{CONCLUSIONS}

From our results, current evaluation method does not fulfill the actual goals due to incomplete questionnaire. This will lead to misleading the concepts behind the experiment for students rather than what they gained. Most of the evaluation used one type of questionnaire, easy to express their opinion or appears as difficult. Most of the assessment takes limited time and will be a problem if the students are at the risk. From our studies, whatever is the assessment method, questionnaire itself should be asked in different form, where students have an opportunity to answer fully by 
selecting their easy type. Hence preparation of combined questionnaire in the protocol can analyze the depth of understanding knowledge among students especially no reflective learners and teachers in science related education.

\section{Acknowledgement}

The author would like to acknowledge MHRD Virtual labs mission to carry out this research

\section{REFERENCES}

1. K. Achuthan, L. S. Bose, S. Francis, K. S. Sreelatha, C. O. Sreekala, P. Nedungadi, et al., 'Improving perception of invisible phenomena in undergraduate physics education using ICT', 2014 2nd International Conference on Information and Communication Technology (ICoICT), pp. 226231, 2014

2. Achuthan, K., Brahmanandan, S., Bose, $L$. 'Cognitive load Management in Multimedia Enhanced Interactive Virtual Laboratories', Advances in intelligent informatics, advances in intelligent systems and computing. Springer international publishing, Cham, p. Pp 143155,2015

3. American Association of Physics Teachers, "Goals of the Introductory Physics Laboratory", American Journal of Physics, vol. 66, no. 6, pp. 483-485, Jun 1998.

4. Baird, J. 'Beliefs and practice in teacher assessment, Assessment in Education: Principles, Policy and Practice, 17 (1), 1-5 2010

5. Baird, J. 'Examinations versus teacher assessments, Assessment in Education: Principles, Policy and Practice', 17 (3), 251-254, 2010

6. Baird, J. 'Macro and micro influences on assessment, Assessment in Education: Principles, Policy and Practice, 16 (2), 127-129. 2009

7. Daly, A., Baird, J., Chamberlain, S. \& Meadows, M. 'Assessment reform: students' and teachers' responses to the introduction of stretch and challenge at A-level, Curriculum Journal, 23 (2), 173-187 2012.

8. Maddalena Taras, Summative and formative assessment: Perceptions and realities Active Learning in Higher Education 9: 172-192, July 2008

9. Margaret Wegener, Timothy J. McIntyre and Dominic McGrath, "Developing a virtual physics world", Australasian Journal of Educational Technology, vol. 28, no. 3, pp. 504-521, 2012

10. N. Erdemir, "Determining student's attitude towards physics through problem solving strategy", Asia-Pacific Forum on Science Learning and Teaching, vol 10, no. 2, pp. 1, 2009.

11. Oliver, M. "An introduction to the evaluation of learning technology”, Educational Technology \& Society, Vol 3, No 4, pp 20-30, 2000.
12. N. Rutten, W. R. van Joolingem, J. T. van der Veen, "The Learning Effects of Computer Simulations in Science Education", 58, pp. 136-153, 2012.

13. R. Trumper, "The Physics Laboratory - A Historical Overview and Future Perspectives", Science \& Education 12, pp. 645-670, 2003

14. R.M. Felder and L.K. Silverman, "Learning and Teaching Styles in Engineering Education," Engr. Education, 78(7), 674-681,1998

15. Victoria Simpson-Beck, Assessing classroom assessment techniques Active Learning in Higher Education July 2011 12: 125-132 